British Journal of Nutrition (2020), 124, 23-33

doi:10.1017/S0007114520000689

(c) The Authors 2020. This is an Open Access article, distributed under the terms of the Creative Commons Attribution licence (http:// creativecommons.org/licenses/by/4.0/), which permits unrestricted re-use, distribution, and reproduction in any medium, provided the original work is properly cited.

\title{
Organic selenium supplement partially alleviated diquat-induced oxidative insults and hepatic metabolic stress in nursery pigs
}

\author{
Nicole Doan ${ }^{1}$, Yanhong $\mathrm{Liu}^{2}$, Xia Xiong ${ }^{2,3}$, Kwangwook Kim² ${ }^{2}$ Zhaohai Wu ${ }^{2,4}$, David M. Bravo $†$, \\ Alexandra Blanchard ${ }^{5}$ and Peng $\mathrm{Ji}^{1 *}$ \\ ${ }^{1}$ Department of Nutrition, University of California, Davis, CA 95616, USA \\ ${ }^{2}$ Department of Animal Science, University of California, Davis, CA 95616, USA \\ ${ }^{3}$ Key Laboratory of Agro-ecological Processes in Subtropical Region, National Engineering Laboratory for Pollution Control and \\ Waste Utilization in Livestock and Poultry Production, Institute of Subtropical Agriculture, Chinese Academy of Sciences, \\ Changsha, Hunan 210125, People's Republic of China \\ ${ }^{4}$ Institute of Animal Sciences, Chinese Academy of Agricultural Sciences, Beijing 100193, People's Republic of China \\ ${ }^{5}$ Pancosma SA, 1180 Rolle, Switzerland
}

(Submitted 20 September 2019 - Final revision received 11 February 2020 - Accepted 12 February 2020 - First published online 2 March 2020)

\section{Abstract}

The study investigated antioxidant effects of Se on resilience to diquat-induced oxidative stress in nursery pigs. Thirty-five weaned pigs were individually housed and randomly assigned to one of the five treatments. Pigs were (1) fed a basal diet and intraperitoneally injected with sterile saline (negative control), (2) fed the basal diet and injected with diquat solution (positive control, PC), or fed the basal diet supplemented with $0.3 \mathrm{mg} \mathrm{Se} / \mathrm{kg}$ as (3) sodium selenite (SS), (4) soyabean protein-chelated Se (SC) or (5) selenised yeast (SY) and intraperitoneally injected with diquat. Pigs were fed the experimental diets for $17 \mathrm{~d}$ and injected with diquat at $10 \mathrm{mg} / \mathrm{kg}$ body weight or saline on the 11 th day of the study (day 0 post-injection (PI)). Diquat exposure induced acute stress and innate immune activation $(P<0.05)$ at $6 \mathrm{~h}$ PI and compromised $(P<0.05)$ plasma glutathione peroxidase activity on day $2 \mathrm{PI}$, which was accompanied by an increase in plasma malondialdehyde at $6 \mathrm{~h}$ and day $2 \mathrm{PI}(P<0 \cdot 10)$. Organic Se, particularly SY, enhanced $(P<0 \cdot 05)$ endogenous antioxidant activity in various aspects compared with the PC group. The growth rate and feed intake from day 0 to day 7 PI were significantly lower in the PC, SS and SC groups than the NC group $(P<0 \cdot 05)$. Untargeted metabolomics analysis revealed that twenty-two hepatic metabolites (false discovery rate $<0 \cdot 15$ ) associated with lipid and cellular antioxidant metabolism were altered by diquat. SY restored hepatic metabolic profiles in some but not all samples.

Key words: Selenium sources: Diquat challenge: Oxidative stress: Nursery pigs: Hepatic metabolomics

Weaning is a stressful event that jeopardises the health and growth of piglets in the swine industry. Heightened oxidative biomarkers have been detected in the gut epithelium, liver and blood circulation of weanling piglets ${ }^{(1,2)}$, suggesting the presence of oxidative stress. Improper management, environmental stressors (i.e. heat stress), oxidised feed, early weaning and infections have all been reported to induce or exacerbate oxidative insults in weaned piglets ${ }^{(1,3,4)}$. Poor post-weaning growth rate has been shown to be associated with heightened blood indicators of oxidative stress and compromised antioxidants pre- and post-weaning ${ }^{(1)}$.

Dietary strategies that enhance endogenous antioxidant capacity are a promising approach to mitigate oxidative stress in weanling pigs ${ }^{(5-7)}$. Se is the cofactor for a number of selenoproteins (i.e. glutathione peroxidises (GPx), thioredoxin reductases, selenoprotein-P) that are critically involved in antioxidative, anti-inflammatory and pro-survival processes ${ }^{(8,9)}$. A good body of evidence suggests that the bioavailability of Se and its effects on antioxidant capacities in humans and animals are influenced by its chemical forms ${ }^{(10-12)}$. For example, in weaned pigs, dietary supplementation of DL-selenomethionine or Se-enriched probiotics (organic Se sources) enhanced antioxidant measurements to a greater extent compared with sodium selenite (SS) ${ }^{(13,14)}$. In comparison with SS and selenised yeast (SY), organic 2-hydroxy-4-methylselenobutanoic acid further increased Se concentration in plasma, liver and muscle of

Abbreviations: AA, ascorbic acid; BW, body weight; GPx, glutathione peroxidase; MDA, malondialdehyde; NC, negative control; PC, positive control; PCA, principal component analysis; PI, post-injection; SC, soya-chelated Se; SOD, superoxide dismutase; SS, sodium selenite; TAC, total antioxidant capacity.

* Corresponding author: Peng Ji, email penji@ucdavis.edu

$\dagger$ Present address: Land O'Lakes Inc., Arden Hills, MN, USA. 
growing gilts ${ }^{(15)}$. Moreover, with increasing dose of Se supplement (5-20 mg Se/kg diet), Se-enriched yeast (organic Se) was associated with more rapid increase in tissue Se deposition compared with SS (inorganic Se) ${ }^{(16)}$. However, supplementing Se above $5 \mathrm{mg} / \mathrm{kg}$ adversely affected intake and growth, of which a sharper decline was observed with inorganic Se compared with organic $\mathrm{Se}^{(16)}$.

All studies discussed above were conducted in healthy pigs under physiological conditions. How Se of different sources affects antioxidant capacity and growth of weanling pigs under oxidative insults is largely unknown. A standardised oxidative stress model is thus critical. Diquat is a bipyridyl herbicide that could utilise molecular $\mathrm{O}_{2}$ to generate superoxide anion radical $^{(17)}$. Exposure to diquat caused rapid production of reactive oxygen species and tissue oxidative damage in laboratory animals ${ }^{(18,19)}$ and livestock species, including pigs ${ }^{(7,20-22)}$. The liver has been shown to be the main target organ of diquat-induced oxidative insults ${ }^{(18,19)}$. The present study evaluated effects of Se supplements on resilience and hepatic metabolic response to diquat-induced oxidative stress in weanling pigs. Three sources of Se supplements were compared in the present study including SS, SY and soya-chelated Se (SC), which is a novel Se supplement that was produced by chelating SS with hydrolysed soyabean protein.

\section{Materials and methods}

\section{Animal care and experimental design}

The protocol (no. 19322) for this experiment was approved by the Institute of Animal Care and Use Committee at the University of California, Davis. The experiment was conducted in Cole facility at University of California, Davis. A total of thirty-five cross-bred pigs (Duroc $\times$ Yorkshire $\times$ Landrace; initial body weight (BW) 9.72 (SD 1.39) kg) including twenty barrows and fifteen gilts were blocked by sex and litter and were randomly assigned to one of the five treatments ( $n 7 /$ treatment) at 1 week after weaning (approximately $28 \mathrm{~d}$ of age). Pigs were individually housed in crates enriched with toys (pen size $0.61 \times 1.22 \mathrm{~m}$ ) with free access to experimental diet and water throughout the $17-\mathrm{d}$ study.

Pigs in the negative control (NC) or positive control (PC) groups were fed a basal diet without Se supplement and intraperitoneally injected with sterile saline (NC) or diquat (PC) on the 11th day of the study (day 0 relative to injection). Pigs in Se supplement groups were fed the basal diet supplemented with $0.3 \mathrm{mg} \mathrm{Se} / \mathrm{kg}$ in the form of SS, SC or SY and intraperitoneally injected with diquat on the 11th day of the study. The study lasted for $17 \mathrm{~d}$ covering $10 \mathrm{~d}$ pre- and $7 \mathrm{~d}$ post-injection (PI) of diquat. All Se products were provided by Pancosma, S.A. The Se content was $46 \%(\mathrm{w} / \mathrm{w})$ in SS, $2.9 \%$ in SC and $0.22 \%$ in $\mathrm{SY}$. The basal diet was formulated to meet the nutrient requirements for nursery pigs with the exception of dietary Se concentration $(<0.2 \mathrm{mg} / \mathrm{kg}$ as-fed basis) which was below the Se recommendation of $0.3 \mathrm{mg} / \mathrm{kg}$ (Table 1). Representative samples of experimental diets were submitted to Cumberland Valley Analytical Services for analyses of macronutrients and University of Missouri Agricultural Experiment Station
Table 1. Ingredient and nutrient composition of the basal diets

\begin{tabular}{lc}
\hline Items & Basal diet* \\
\hline Ingredients (\%) & \\
Maize & 44.51 \\
Dried whey & 15.00 \\
Soyabean meal & 14.00 \\
Fishmeal & 10.00 \\
Soya protein concentrate & 7.00 \\
Lactose & 6.00 \\
Soyabean oil & 2.00 \\
Limestone & 0.56 \\
L-Lysine-HCl & 0.15 \\
DL-Methionine & 0.06 \\
L-Threonine & 0.02 \\
Salt & 0.40 \\
Vitamin-mineral premix $¥$ & 0.30 \\
Total & 100.00 \\
Analysed nutrients (\% as-fed) & \\
DM & 89.5 \\
Crude protein & 21.21 \\
Acid-detergent fibre & 3.49 \\
Neutral-detergent fibre & 7.61 \\
Ca & 0.89 \\
P & 0.59 \\
Se§ (mg/kg) & $<0.20$ \\
&
\end{tabular}

* Pigs in the negative control and positive control groups were fed the basal diet without Se supplements. Pigs in Se-supplement groups were fed the basal diet supplemented with $0.3 \mathrm{mg} \mathrm{Se} / \mathrm{kg}$ diet from sodium selenite (SS), soyabean proteinchelated Se (SC) or selenised yeast (SY).

† No Se supplement was added to the basal diet. Se supplement was first mixed well with the premix and $500 \mathrm{~g}$ of maize meal before mixing with other ingredients of the basal diet. Se accounts for $46,2.9$ and $0.22 \%$ in SS, SC and SY, respectively. SS, SC and SY were supplemented at $0.66,10.34$ and $136.36 \mathrm{mg} / \mathrm{kg}$ in the basal diet, respectively, to provide $0.3 \mathrm{mg} \mathrm{Se} / \mathrm{kg}$ diet.

¥ Provided the following quantities of vitamins and micro-minerals per $\mathrm{kg}$ of complete diet: Vitamin A as retinyl acetate, $3340.8 \mu \mathrm{g}$; vitamin $D_{3}$ as cholecalciferol, $55.2 \mu \mathrm{g}$; vitamin $\mathrm{E}$ as DL- $\alpha$ tocopheryl acetate, $44.2 \mu \mathrm{g}$; vitamin $\mathrm{K}$ as menadione dimethylpyrimidinol bisulphite, $1.42 \mathrm{mg}$; thiamin as thiamine mononitrate, $0.24 \mathrm{mg}$; riboflavin, $6.59 \mathrm{mg}$; pyridoxine as pyridoxine hydrochloride, $0.24 \mathrm{mg}$; vitamin $\mathrm{B}_{12}$, $0.03 \mathrm{mg}$; D-pantothenic acid as D-calcium pantothenate, $23.5 \mathrm{mg}$; niacin, $44.1 \mathrm{mg}$; folic acid, $1.59 \mathrm{mg}$; biotin, $0.44 \mathrm{mg}$; $\mathrm{Cu}, 20 \mathrm{mg}$ as copper sulphate and copper chloride; $\mathrm{Fe}, 126 \mathrm{mg}$ as ferrous sulphate; iodine, $1.26 \mathrm{mg}$ as ethylenediamine dihydriodide; $\mathrm{Mn}, 60.2 \mathrm{mg}$ as manganese sulphate; and $\mathrm{Zn}, 125.1 \mathrm{mg}$ as zinc sulphate.

$\S$ Analysed Se content of SS, SC and SY diets was $0.4 \mathrm{mg} / \mathrm{kg}$

Chemical Laboratories for analysis of Se content. Pigs were weighed at the beginning of the study (day -10), the day of diquat injection (day 0) and at the end of the experiment (day 7 PI). Daily feed allotments were recorded to calculate average daily gain, average daily feed intake and gain:feed ratio. Pigs were euthanised on day 7 PI for tissue sample collection.

\section{Diquat injection}

On day 0 PI, all pigs except those in the NC group were intraperitoneally injected with diquat (Diquat dibromide monohydrate; Sigma-Aldrich, Inc.) at $10 \mathrm{mg}$ diquat ion $/ \mathrm{kg} \mathrm{BW}$. Diquat injections were prepared by dissolving diquat powder in $0.9 \%$ sterile saline solution to a final concentration of $10 \mathrm{mg} / \mathrm{ml}$. Pigs in the NC group were intraperitoneally injected with $10 \mathrm{ml}$ of $0.9 \%$ sterile saline solution.

\section{Total and differential blood cell counts}

Whole blood samples were collected from jugular vein at $0 \mathrm{~h}$ (prior to diquat injection), $6 \mathrm{~h}, 24 \mathrm{~h}, 2 \mathrm{~d}, 4 \mathrm{~d}$ and $7 \mathrm{~d}$ PI and 
submitted to Comparative Pathology Laboratory at University of California, Davis. Total and differential blood cell counts were determined using a multiparameter, automated haematology analyser (Drew/ERBA Scientific 950 FS Hematological Analyzer; Drew Scientific Inc.) following a protocol that was previously optimised for porcine blood samples.

\section{Plasma antioxidant enzymes, lipid peroxidation and cortisol concentration}

Plasma was harvested from a portion of blood samples through centrifugation at $1500 \boldsymbol{g}$ for $15 \mathrm{~min}$ at $4^{\circ} \mathrm{C}$ and stored at $-80^{\circ} \mathrm{C}$ until analysis. The activities of GPx (catalogue no. 703102), superoxide dismutase (SOD; catalogue no. 706002), total antioxidant capacity (TAC; catalogue no. 709001) and plasma malondialdehyde (MDA; catalogue no. 700870) concentration were analysed through colorimetric assays using commercial kits (Cayman Chemical). The result of SOD activity was presented as $\mathrm{U} / \mathrm{ml}$ with the unit of SOD defined as the amount of enzyme needed to exhibit $50 \%$ dismutation of the superoxide radical. The activity of GPx was indirectly detected through determining the oxidation of NADPH to $\mathrm{NADP}^{+}$and presented as $\mathrm{nmol} / \mathrm{min}$ per $\mathrm{ml}$. The TAC was calculated based on a standard curve generated using Trolox and presented as mmol Trolox $/ \mathrm{ml}$. The total concentration of plasma MDA $(\mu \mathrm{mol} / \mathrm{ml})$ was measured using a thiobarbituric acid-reactive substances assay.

Plasma cortisol concentration. The concentration of cortisol in plasma samples was measured using a commercial ELISA kit (catalogue no. KGE008B; R\&D Systems, Inc.). The result was calculated based on the absorbance at $450 \mathrm{~nm}$ and referenced to a standard curve.

\section{Hepatic antioxidant enzymes and lipid peroxidation}

Liver samples collected after euthanasia were snap-frozen in liquid $\mathrm{N}_{2}$ and stored at $-80^{\circ} \mathrm{C}$ until analysis. Liver tissue (approximately $200 \mathrm{mg}$ ) was homogenised using a glass tissue grinder in $2 \mathrm{ml}$ ice-cold lysis buffer containing a cocktail of protease inhibitors (Sigma-Aldrich, Inc.). The liver homogenate was centrifuged at $10000 \boldsymbol{g}$ for $5 \mathrm{~min}$ at $4^{\circ} \mathrm{C}$ to harvest supernatant for assays of antioxidant enzymes and lipid peroxidation. The activities of GPx, SOD, TAC and catalase, and MDA concentration in liver samples were analysed using the same kits stated previously. The activity of catalase in liver samples was determined using a commercial kit (catalogue no. 707002; Cayman Chemical). The kit measures product formation from the reaction of catalase with methanol in the presence of hydrogen peroxide $\left(\mathrm{H}_{2} \mathrm{O}_{2}\right)$. The concentration of total protein in liver homogenate was determined using Pierce Micro BCA Protein Assay kit (Thermo Scientific). The final results of antioxidant parameters were normalised with total protein concentration in each sample. The results of GPx, SOD, TAC and catalase were expressed in $\mathrm{nmol} / \mathrm{min}$ per $\mathrm{mg}$ protein, $\mathrm{U} / \mathrm{mg}$ protein, $\mathrm{mmol}$ Trolox $/ \mathrm{mg}$ protein, $\mu \mathrm{mol}$ formaldehyde/min per mg protein, respectively. The MDA concentration was expressed in $\mu \mathrm{mol} / \mathrm{mg}$ protein.

\section{Untargeted metabolomics analysis}

Liver samples from the NC, PC and SY groups were submitted for metabolomics analysis. The analysis was performed by the NIH West Coast Metabolomics Center using GC (Agilent 6890) coupled with time-of-flight MS (Leco Pegasus IV). Samples were processed based on the modified procedures as previously stated by others ${ }^{(23,24)}$. Briefly, liver samples (approximately $10 \mathrm{mg}$ ) were mixed with $1 \mathrm{ml}$ extraction solvent (acetonitrile, isopropanol and water in proportion 3:3:2) and homogenised for $45 \mathrm{~s}$. Then, the homogenate was centrifuged for $2 \mathrm{~min}$ at $14000 \boldsymbol{g}$ to generate supernatant, which was completely dried using a cold-trap vacuum concentrator (Labconco Centrivap). Dried samples were subsequently resuspended in $500 \mu \mathrm{l}$ of a $50 \%$ aqueous acetonitrile solution and centrifuged (14 $000 \boldsymbol{g}$ for $2 \mathrm{~min}$ ) to remove membrane lipids and TAG. The sample was concentrated and derivatised and then mixed with $1 \mu \mathrm{l}$ of internal markers (C8-C30 fatty acid methyl esters). The derivatised sample was injected for GC time-of-flight MS analysis as previously described ${ }^{(24)}$. All samples were analysed in one batch. The raw spectral data were first processed using Leco ChromaTOF software (version 2.32) for peak identification and mass spectra deconvolution. The spectral data were further refined using the BinBase algorithm ${ }^{(25)}$. All metabolite spectra in BinBase were matched against the Fiehn mass spectral library and the NIST spectral library based on the retention index and mass spectrum. The mapped metabolites were reported for compound names and signal intensity of peak height (counts per spectrum).

\section{Statistical and bioinformatics analysis}

Data were verified for normal distribution using the UNIVARIATE procedure of SAS and analysed using the PROC MIXED of SAS (SAS Institute). The statistical model included treatment as the fixed effect, while blocks and pigs were included as random effects. Least squares means of treatment effect were calculated, and the mean separation was performed through PDIFF function when significant treatment effect was detected. Statistical significance was considered at $P \leq 0.05$, and trend towards significance was considered at $P \leq 0 \cdot 10$.

Statistical and bioinformatics analyses for identified and unidentified metabolites were performed separately. The metabolomics data of peak intensity were subjected to natural-logarithmic transformation and autoscaling before a Student's $t$ test that was performed using PROC MULTTEST of SAS (version 9.4) with Benjamini-Hochberg adjustment for multiple tests. Significance was declared at $P \leq 0 \cdot 05$, and the false discovery rate-adjusted $P$ value $(q$ value $) \leq 0 \cdot 15$. Metabolites that were significantly impacted were uploaded to MetaboAnalyst (https://www.metaboanalyst.ca/) for pathway enrichment analysis and clustering analysis. To identify the predictors of metabolic difference, multivariate modelling including principal component analysis (PCA) was performed on the data set of identified metabolites through built-in R statistics in MetaboAnalyst. Score plots were generated to visualise the top two sources of variance. 

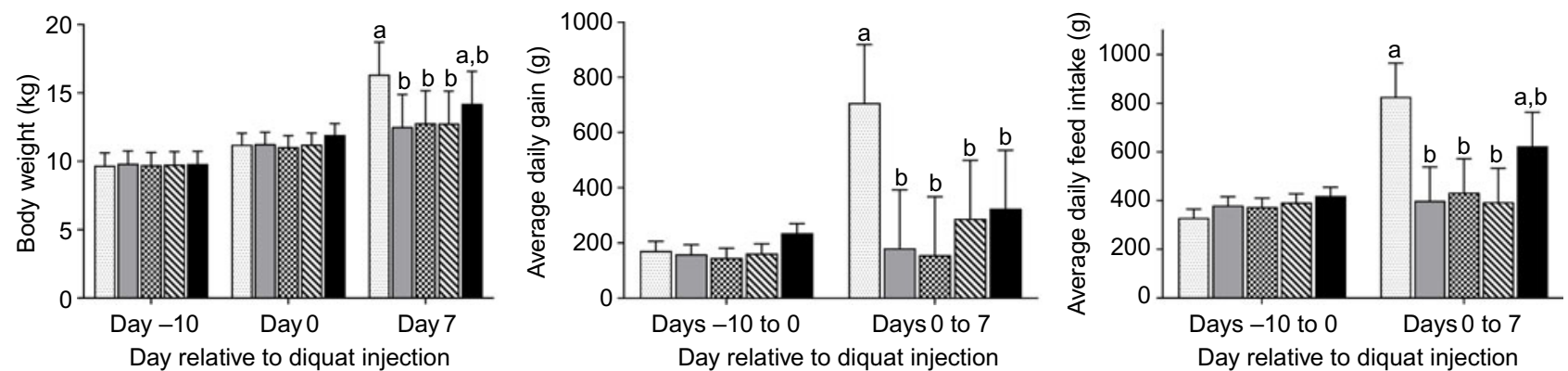

Fig. 1. Growth performance and feed intake of piglets ( $n$ 7/treatment) in response to diquat challenge and dietary selenium supplementation. Values were presented as least square means with their standard errors. ${ }^{a, b}$ Mean values with unlike letters were significantly different $(P<0.05)$. $\square$, Negative control without diquat challenge nor dietary selenium supplementation; $\square$, positive control with diquat challenge without dietary selenium supplementation; $:$, sodium selenite group with diquat challenge; $\mathbb{S}$, soya protein-chelated selenium group with diquat challenge; $\mathbf{\square}$, selenised yeast group with diquat challenge.

\section{Results}

\section{Growth and feed intake}

No difference was observed in BW among treatment groups on day -10 or day 0 (Fig. 1). The final BW of pigs in the NC group was significantly higher $(P<0.05)$ than that of diquat-challenged pigs on day $7 \mathrm{PI}$, with the exception that the final BW of pigs in SY was not statistically different from any other group. Neither average daily gain nor average daily feed intake was different among groups from day -10 to day 0 . In comparison with the NC group, diquat injection significantly reduced $(P<0.05)$ average daily feed intake and average daily gain from day 0 to day 7 PI with the exception that the average daily feed intake of SY was not statistically different from the other groups.

\section{Leucocyte profiles}

Total leucocyte count did not differ among treatments prior to diquat injection (Table 2). The cell counts of leucocyte and neutrophil were significantly greater in the PC group than other groups at $6 \mathrm{~h}$ PI $(P<0 \cdot 05)$. Lymphocyte count was significantly greater in Se-supplemented groups than that of the NC group at $6 \mathrm{~h}$ PI $(P<0 \cdot 05)$. All groups injected with diquat had a higher ratio of neutrophils:lymphocytes than the NC group at $6 \mathrm{~h}$ PI $(P<0.05)$. Pigs in the PC and SS groups had more leucocytes than the NC group and more lymphocytes than the NC and SY groups on day 4 PI $(P<0 \cdot 05)$.

\section{Plasma cortisol concentration}

Treatment did not affect plasma cortisol concentration on day 0 PI (Table 2). Diquat injection significantly increased $(P<0.01)$ plasma cortisol at $6 \mathrm{~h}$ PI compared with the NC group. In comparison with the PC group, dietary supplementation of Se significantly reduced plasma cortisol at $6 \mathrm{~h}(P<0 \cdot 01)$ with the greatest reduction induced by SY. There was a trend of treatment effect at $24 \mathrm{~h}(P=0.09)$, on day $2(P=0.07)$ and day $4 \mathrm{PI}(P=0.07)$. Plasma cortisol was the highest in the PC group at $24 \mathrm{~h}$ and on day 2 and the lowest in the SY group on day 2 and day 4 .

\section{Lipid peroxidation and antioxidant activity}

Supplementation of SY enhanced plasma GPx activity compared with NC, PC and SS groups on day 0 PI $(P<0 \cdot 05$; Table 3$)$. The plasma GPx activity was lower in the PC and SS groups compared with the SY group at $6 \mathrm{~h}$ PI or compared with both the SY and NC groups on day 2 PI $(P<0 \cdot 05)$. Despite lack of treatment effect on day 4 PI, a trend of treatment effect on plasma GPx activity was detected on day 7 PI $(P=0.09)$, wherein highest activity was observed in the SY group, followed by NC, SS, SC and PC. There was a significant treatment effect on plasma SOD activity at $24 \mathrm{~h}$, on days 2,4 and 7 PI $(P<0.05)$. At $24 \mathrm{~h}$, the plasma SOD activity was higher in SC and SY compared with NC and PC $(P<0.05)$ and was higher in SS compared with NC. SY and SS had the highest plasma SOD activity on day 2 and day 4 PI. It was significantly different in comparison with NC on day 2 PI or both NC and PC on day 4 PI $(P<0.05)$. On day 7 PI, the highest plasma SOD activity was detected in SC, which was significantly different from SS, NC and PC $(P<0 \cdot 05)$. Pigs in the SY group had higher SOD activity than those in the PC group on day 7 PI $(P<0.05)$. Plasma TAC was significantly higher in the SS and SC groups than in the NC and PC groups on day 2 PI $(P<0.05)$. There was a trend of treatment effect on plasma TAC on day 0 , at $6 \mathrm{~h}$, and $24 \mathrm{~h} \mathrm{PI}(P \leq 0 \cdot 10)$. It was generally greater in the Se-supplemented groups compared with the $\mathrm{PC}$ and $\mathrm{NC}$ groups. There was a trend $(P=0.09)$ of treatment effect on plasma MDA concentration at $6 \mathrm{~h}$ and on day $2 \mathrm{PI}$. Highest plasma concentration of MDA was observed in PC in both time points.

Treatment significantly affected liver SOD and GPx activity $(P<0.05)$ and tended to affect liver catalase activity $(P=0.07)$ and MDA concentration $(P=0 \cdot 09)$, but had no effect on liver TAC. The liver SOD activity was lower in the PC group than that in the NC and SC groups $(P<0.05$; Table 4$)$, whereas the liver GPx activity was the lowest in the SS group followed by the $\mathrm{PC}$ and SC groups and was the highest in the NC and SY groups $(P<0.05)$. Liver catalase activity and MDA concentration were the highest in the PC group compared with other groups.

\section{Liver metabolites}

In the liver, 700 metabolites were detected, of which 203 were identified. Twenty-two metabolites were significantly different between the NC and PC groups (false discovery rate $<0 \cdot 15$ ) (Table 5, Fig. 2). Hierarchical clustering analysis further revealed greater within-group resemblance in metabolite profiles in both PC and NC liver samples (Fig. 3). In PCA analysis between PC and $\mathrm{NC}$, the top two components explained $42.6 \%$ of variance. 
Table 2. Effect of dietary supplementation of selenium on leucocyte profiles and plasma cortisol concentration of weanling pigs in response to diquat injection $(n 6)$

(Mean values with their standard errors; 6-7 observations per least square mean value)

\begin{tabular}{|c|c|c|c|c|c|c|c|}
\hline \multirow[b]{2}{*}{ Items } & \multicolumn{5}{|c|}{ Diquat challenge } & \multirow[b]{2}{*}{ SEM } & \multirow[b]{2}{*}{$P$} \\
\hline & NC & PC & SS & SC & SY & & \\
\hline \multicolumn{8}{|l|}{ Day 0 before infection } \\
\hline Leucocytes $\left(10^{3} / \mu \mathrm{l}\right)$ & 11.61 & 11.45 & $12 \cdot 24$ & $11 \cdot 11$ & 10.50 & 1.78 & 0.97 \\
\hline Neutrophils $\left(10^{3} / \mu \mathrm{l}\right)$ & 5.04 & 5.29 & $5 \cdot 20$ & 5.46 & $4 \cdot 61$ & $1 \cdot 18$ & 0.99 \\
\hline Lymphocytes $\left(10^{3} / \mu l\right)$ & 5.37 & 4.80 & $5 \cdot 60$ & 4.35 & 4.62 & 0.98 & 0.83 \\
\hline Neutrophils:lymphocytes & 0.925 & 1.098 & 1.007 & 1.342 & $1 \cdot 120$ & 0.359 & 0.88 \\
\hline Cortisol (ng/ml) & $26 \cdot 28$ & $29 \cdot 18$ & $27 \cdot 76$ & 28.26 & 29.51 & 3.82 & 0.86 \\
\hline \multicolumn{8}{|l|}{$6 \mathrm{~h} \mathrm{PI}$} \\
\hline Leucocytes $\left(10^{3} / \mu \mathrm{l}\right)$ & $13 \cdot 96^{\mathrm{b}}$ & $17 \cdot 54^{\mathrm{a}}$ & $12 \cdot 49^{b}$ & $12 \cdot 86^{\mathrm{b}}$ & $12 \cdot 36^{b}$ & 1.78 & $<0.05$ \\
\hline Neutrophils $\left(10^{3} / \mu l\right)$ & $6 \cdot 67^{\mathrm{b}}$ & $11.42^{\mathrm{a}}$ & $7 \cdot 77^{\mathrm{b}}$ & $8 \cdot 34^{\mathrm{b}}$ & $7 \cdot 78^{\mathrm{b}}$ & 1.18 & $<0.05$ \\
\hline Lymphocytes $\left(10^{3} / \mu l\right)$ & $5 \cdot 88^{\mathrm{a}}$ & $4.58^{a, b}$ & $3.78^{\mathrm{b}}$ & $3 \cdot 29^{b}$ & $3.43^{\mathrm{b}}$ & 0.98 & $<0.05$ \\
\hline Neutrophils:lymphocytes & $1.428^{\mathrm{b}}$ & $3.089^{a}$ & $2 \cdot 393^{a}$ & $3.063^{a}$ & $3.125^{\mathrm{a}}$ & 0.359 & $<0.01$ \\
\hline Cortisol (ng/ml) & $26 \cdot 70^{c}$ & $88.55^{\mathrm{a}}$ & $63 \cdot 72^{\mathrm{b}}$ & $56 \cdot 01^{\mathrm{b}}$ & $47 \cdot 26^{b, c}$ & 11.01 & $<0.01$ \\
\hline \multicolumn{8}{|l|}{$24 \mathrm{~h} \mathrm{PI}$} \\
\hline Leucocytes $\left(10^{3} / \mu \mathrm{l}\right)$ & $14 \cdot 12$ & $16 \cdot 24$ & 14.81 & 13.75 & 13.89 & 1.78 & 0.82 \\
\hline Neutrophils $\left(10^{3} / \mu \mathrm{l}\right)$ & 5.89 & 7.99 & 7.53 & 6.57 & 6.53 & $1 \cdot 18$ & 0.62 \\
\hline Lymphocytes $\left(10^{3} / \mu l\right)$ & 6.95 & 6.77 & $6 \cdot 01$ & $5 \cdot 76$ & 5.90 & 0.98 & 0.82 \\
\hline Neutrophils:lymphocytes & 0.932 & 1.235 & 1.391 & 1.278 & $1 \cdot 248$ & 0.359 & 0.86 \\
\hline Cortisol (ng/ml) & 29.62 & 48.05 & 32.55 & 39.00 & 32.56 & 4.95 & 0.09 \\
\hline \multicolumn{8}{|l|}{$2 \mathrm{dPI}$} \\
\hline Leucocytes $\left(10^{3} / \mu \mathrm{l}\right)$ & 14.94 & 17.95 & $16 \cdot 26$ & 17.05 & 17.29 & 1.82 & 0.73 \\
\hline Neutrophils $\left(10^{3} / \mu l\right)$ & 7.09 & 8.88 & 8.25 & $9 \cdot 13$ & 9.51 & 1.21 & 0.52 \\
\hline Lymphocytes $\left(10^{3} / \mu \mathrm{l}\right)$ & 6.43 & 7.68 & 6.75 & 6.53 & 6.32 & 1.00 & 0.79 \\
\hline Neutrophils:lymphocytes & $1 \cdot 151$ & 1.232 & $1 \cdot 271$ & 1.507 & $2 \cdot 169$ & 0.365 & 0.09 \\
\hline Cortisol (ng/ml) & $26 \cdot 31$ & 38.27 & $29 \cdot 10$ & 34.67 & 28.65 & 4.70 & 0.07 \\
\hline \multicolumn{8}{|l|}{$4 \mathrm{dPI}$} \\
\hline Leucocytes $\left(10^{3} / \mu \mathrm{l}\right)$ & $14.71^{\mathrm{b}}$ & $18 \cdot 49^{a}$ & $18 \cdot 97^{\mathrm{a}}$ & $16 \cdot 56^{a, b}$ & $15 \cdot 31^{a, b}$ & 1.86 & $<0.05$ \\
\hline Neutrophils $\left(10^{3} / \mu \mathrm{l}\right)$ & 6.96 & 8.44 & 9.62 & $8 \cdot 21$ & 8.29 & 1.23 & 0.53 \\
\hline Lymphocytes $\left(10^{3} / \mu \mathrm{l}\right)$ & $6 \cdot 68^{\mathrm{b}}$ & $8.89^{\mathrm{a}}$ & $8.05^{\mathrm{a}}$ & $7 \cdot 10^{a, b}$ & $5.89^{b}$ & 1.02 & $<0.05$ \\
\hline Neutrophils:lymphocytes & 1.270 & 0.966 & 1.206 & 1.325 & 1.507 & 0.372 & 0.82 \\
\hline Cortisol (ng/ml) & $22 \cdot 24$ & $28 \cdot 22$ & $22 \cdot 26$ & 38.28 & $21 \cdot 15$ & $5 \cdot 25$ & 0.07 \\
\hline \multicolumn{8}{|l|}{$7 \mathrm{~d} \mathrm{PI}$} \\
\hline Leucocytes $\left(10^{3} / \mu \mathrm{l}\right)$ & $11 \cdot 28$ & 13.84 & 12.63 & 11.79 & 11.31 & 1.85 & 0.81 \\
\hline Neutrophils $\left(10^{3} / \mu l\right)$ & 4.87 & 7.01 & 5.65 & 5.68 & $5 \cdot 22$ & 1.23 & 0.67 \\
\hline Lymphocytes $\left(10^{3} / \mu \mathrm{l}\right)$ & 5.32 & 5.59 & 5.74 & 5.09 & 4.97 & 1.02 & 0.98 \\
\hline Neutrophils:lymphocytes & 0.969 & 1.362 & 1.073 & 1.337 & 1.159 & 0.371 & 0.87 \\
\hline Cortisol (ng/ml) & 27.68 & $30 \cdot 33$ & 28.25 & 33.47 & 22.01 & 5.56 & 0.39 \\
\hline
\end{tabular}

NC, negative control; PC, positive control; SS, sodium selenite; SC, soyabean protein-chelated Se; SY, selenised yeast; PI, post-injection.

$\mathrm{a}, \mathrm{b}, \mathrm{c}$ Mean values in a row with unlike superscript letters were significantly different $(P<0.05)$

The distribution of samples was largely separated by treatment suggesting notable effect of diquat on liver metabolome. None of the hepatic metabolites was different between SY and NC or between SY and PC (data not shown). PCA revealed relatively greater similarity in distribution pattern between SY and NC (online Supplementary Fig. S1). Substantial individual variations were observed for samples from the SY group.

\section{Discussion}

Effect of selenium supplements on growth performance and antioxidant capacity before diquat challenge

Adequate Se intake critically links to growth and health. Se supplementation has shown to improve growth, dietary nutrient digestibility and utilisation in young rats ${ }^{(26)}$ and weanling pigs ${ }^{(27)}$ that were previously nursed by Se-deficient dams. The underlying mechanism is not fully understood, but impairments in bone metabolism $^{(28)}$ and dysregulated thyroid hormone ${ }^{(29)}$ were considered as contributing factors to Se-deficiency-induced growth retardation. In the present study, Se content in the basal diet $(<0.2 \mathrm{mg} / \mathrm{kg})$ was below recommendation on minimum Se requirement $(0.3 \mathrm{mg} / \mathrm{kg})$ for pigs weighing $5-11 \mathrm{~kg}$. Lack of effect by Se supplements on growth prior to diquat challenge is probably due to a relatively short period of feeding a Se-deficient diet. Although both organic and inorganic forms of Se are efficiently absorbed, organic Se (i.e. selenomethionine and selenocysteine) showed greater tissue and cellular retention than inorganic source of Se in humans and animals ${ }^{(16,30-32)}$. Tissue or plasma GPx activity is a well-accepted biomarker in assessment of bioavailability of dietary $\mathrm{Se}^{(10)}$. Inorganic Se (i.e. selenite) is considered to be more readily converted to hydrogen selenide, the substrate for synthesis of GPx, compared with selenomethionine ${ }^{(10)}$. Studies comparing the effect of Se sources (organic $v$. inorganic) on GPx activity yielded inconsistent results $^{(12,16,33,34)}$. The activity of GPx seemed to be affected by the duration and dose of Se supplements as well. Mahan et $a l^{(12)}$ noted significant interaction between source of Se (selenite $v$. Se-enriched yeast) and Se level on plasma GPx activity showing that organic Se conferred greater activity at 
Table 3. Effect of dietary supplementation of selenium on plasma antioxidant parameters of weanling pigs in response to diquat challenge ( $n 6$ ) (Mean values with their standard errors)

\begin{tabular}{|c|c|c|c|c|c|c|c|}
\hline \multirow[b]{2}{*}{ Items } & \multicolumn{5}{|c|}{ Diquat challenge } & \multirow[b]{2}{*}{ SEM } & \multirow[b]{2}{*}{$P$} \\
\hline & $\mathrm{NC}$ & $\mathrm{PC}$ & SS & SC & SY & & \\
\hline \multicolumn{8}{|l|}{$0 \mathrm{~d}$ (baseline) } \\
\hline SOD (U/ml) & 29.69 & 31.01 & $32 \cdot 29$ & 31.37 & $36 \cdot 61$ & 3.29 & 0.51 \\
\hline GPx (nmol/min per $\mathrm{ml})$ & $303 \cdot 1^{\mathrm{b}}$ & $299 \cdot 1^{\mathrm{b}}$ & $301.9^{b}$ & $391 \cdot 4^{a, b}$ & $421 \cdot 1^{\mathrm{a}}$ & $46 \cdot 37$ & $<0.05$ \\
\hline TAC (mmol Trolox/ml) & $1 \cdot 17$ & 1.39 & $1 \cdot 74$ & 1.51 & 1.44 & 0.20 & 0.07 \\
\hline $\mathrm{MDA}(\mu \mathrm{mol} / \mathrm{ml})$ & $6 \cdot 89$ & $7 \cdot 61$ & $6 \cdot 73$ & 6.45 & 4.86 & $1 \cdot 26$ & 0.43 \\
\hline \multicolumn{8}{|l|}{$6 \mathrm{hPI}$} \\
\hline SOD (U/ml) & 31.87 & $31 \cdot 11$ & 41.50 & 37.56 & $35 \cdot 24$ & 4.51 & 0.25 \\
\hline GPx (nmol/min per ml) & $350 \cdot 6^{a, b}$ & $309 \cdot 9^{b}$ & $320 \cdot 1^{b}$ & $361 \cdot 7^{a, b}$ & $427 \cdot 0^{\mathrm{a}}$ & $36 \cdot 90$ & $<0.05$ \\
\hline TAC (mmol Trolox/ml) & $1 \cdot 30$ & $1 \cdot 31$ & $1 \cdot 76$ & 1.47 & 1.49 & $0 \cdot 18$ & 0.08 \\
\hline $\mathrm{MDA}(\mu \mathrm{mol} / \mathrm{ml})$ & $5 \cdot 87$ & 8.55 & $6 \cdot 26$ & 4.98 & $6 \cdot 36$ & 1.07 & 0.09 \\
\hline \multicolumn{8}{|l|}{$24 \mathrm{~h} \mathrm{PI}$} \\
\hline $\mathrm{SOD}(\mathrm{U} / \mathrm{ml})$ & $24.93^{c}$ & $30 \cdot 76^{b, c}$ & $36 \cdot 33^{a, b}$ & $42 \cdot 20^{a}$ & $39 \cdot 17^{a}$ & 2.94 & $<0.01$ \\
\hline GPx (nmol/min per ml) & $417 \cdot 7$ & $305 \cdot 6$ & $372 \cdot 3$ & $368 \cdot 0$ & $398 \cdot 6$ & $44 \cdot 32$ & 0.47 \\
\hline TAC (mmol Trolox/ml) & $1 \cdot 30$ & 1.55 & $1 \cdot 75$ & $1 \cdot 75$ & 1.68 & $0 \cdot 21$ & 0.10 \\
\hline $\mathrm{MDA}(\mu \mathrm{mol} / \mathrm{ml})$ & 5.54 & $7 \cdot 47$ & $6 \cdot 10$ & $5 \cdot 51$ & $5 \cdot 20$ & 1.01 & 0.13 \\
\hline \multicolumn{8}{|l|}{$2 \mathrm{dPI}$} \\
\hline SOD (U/ml) & $28 \cdot 73^{b}$ & $34 \cdot 34^{a, b}$ & $39 \cdot 17^{\mathrm{a}}$ & $33 \cdot 16^{a, b}$ & $38.55^{a}$ & $3 \cdot 19$ & $<0.05$ \\
\hline GPx (nmol/min per ml) & $397 \cdot 3^{a}$ & $284 \cdot 2^{b}$ & $306 \cdot 8^{b}$ & $360 \cdot 0^{a, b}$ & $394.8^{a}$ & $32 \cdot 74$ & $<0.05$ \\
\hline TAC (mmol Trolox/ml) & $1 \cdot 34^{b}$ & $1 \cdot 30^{b}$ & $1.66^{a}$ & $1.68^{a}$ & $1.46^{a, b}$ & 0.14 & $<0.05$ \\
\hline $\mathrm{MDA}(\mu \mathrm{mol} / \mathrm{ml})$ & $4 \cdot 81$ & $7 \cdot 46$ & $5 \cdot 52$ & $6 \cdot 78$ & $5 \cdot 38$ & 0.82 & 0.09 \\
\hline \multicolumn{8}{|l|}{$4 \mathrm{~d} \mathrm{PI}$} \\
\hline $\mathrm{SOD}(\mathrm{U} / \mathrm{ml})$ & $24.58^{b}$ & $28 \cdot 95^{\mathrm{b}}$ & $41 \cdot 45^{a}$ & $34 \cdot 77^{a, b}$ & $37 \cdot 60^{\mathrm{a}}$ & 2.64 & $<0.01$ \\
\hline GPx (nmol/min per ml) & $398 \cdot 2$ & $307 \cdot 0$ & $367 \cdot 9$ & $335 \cdot 2$ & $401 \cdot 6$ & $56 \cdot 71$ & 0.50 \\
\hline TAC (mmol Trolox/ml) & $1 \cdot 36$ & 1.23 & 1.51 & 1.42 & $1 \cdot 31$ & 0.24 & 0.83 \\
\hline $\operatorname{MDA}(\mu \mathrm{mol} / \mathrm{ml})$ & $4 \cdot 19$ & $5 \cdot 56$ & 4.85 & 4.68 & 4.53 & 0.75 & 0.78 \\
\hline \multicolumn{8}{|l|}{$7 \mathrm{~d} \mathrm{PI}$} \\
\hline $\mathrm{SOD}(\mathrm{U} / \mathrm{ml})$ & $27 \cdot 70^{b, c}$ & $27 \cdot 03^{c}$ & $30 \cdot 35^{b, c}$ & $37 \cdot 66^{a}$ & $33.57^{a, b}$ & 2.63 & $<0.05$ \\
\hline GPx (nmol/min per $\mathrm{ml})$ & $376 \cdot 1$ & $222 \cdot 4$ & 358.9 & $306 \cdot 1$ & $403 \cdot 3$ & 48.08 & 0.09 \\
\hline TAC (mmol Trolox/ml) & 1.41 & 1.40 & 1.59 & $1 \cdot 31$ & $1 \cdot 37$ & 0.15 & 0.70 \\
\hline $\mathrm{MDA}(\mu \mathrm{mol} / \mathrm{ml})$ & $4 \cdot 17$ & 4.67 & $5 \cdot 25$ & $4 \cdot 88$ & 4.93 & 0.99 & 0.95 \\
\hline
\end{tabular}

NC, negative control; PC, positive control; SS, sodium selenite; SC, soyabean protein-chelated Se; SY, selenised yeast; baseline, before injection; SOD, superoxide dismutase; GPX, glutathione peroxidase; TAC, total antioxidant capacity; MDA, malondialdehyde; $\mathrm{PI}$, post-injection.

a,b,c Mean values within a row with unlike superscript letters were significantly different $(P<0.05)$.

Table 4. Impact of dietary supplementation of selenium on liver antioxidant enzymes and lipid peroxidation adduct (malondialdehyde, MDA) in piglets in response to diquat challenge $(n 6)$

(Mean values with their standard errors; six observations per least square mean value)

\begin{tabular}{|c|c|c|c|c|c|c|c|}
\hline \multirow[b]{2}{*}{ Items } & \multicolumn{5}{|c|}{ Diquat challenge } & \multirow[b]{2}{*}{ SEM } & \multirow[b]{2}{*}{$P$} \\
\hline & NC & $\mathrm{PC}$ & SS & $\mathrm{SC}$ & SY & & \\
\hline SOD (U/mg protein) & $0.245^{\mathrm{a}}$ & $0 \cdot 124^{b}$ & $0.192^{a, b}$ & $0.244^{\mathrm{a}}$ & $0.181^{a, b}$ & 0.043 & $<0.05$ \\
\hline TAC (mmol Trolox/mg protein) & 0.031 & 0.028 & 0.023 & 0.034 & 0.032 & 0.01 & 0.24 \\
\hline Catalase ( $\mu \mathrm{mol}$ formaldehyde/min per mg protein) & $170 \cdot 76$ & $281 \cdot 76$ & 173.04 & $223 \cdot 12$ & 210.58 & 36.86 & 0.07 \\
\hline MDA ( $\mu \mathrm{mol} / \mathrm{mg}$ protein) & 0.943 & 1.136 & 0.822 & 1.011 & 0.875 & 0.69 & 0.09 \\
\hline
\end{tabular}

NC, negative control; PC, positive control; SS, sodium selenite; SC, soyabean protein-chelated Se; SY, selenised yeast; SOD, superoxide dismutase; GPx, glutathione peroxidase; TAC, total antioxidant capacity; MDA, malondialdehyde.

a,b,c Mean values within a row with unlike superscript letters were significantly different $(P<0.05)$

0.2 and $0.3 \mathrm{mg} / \mathrm{kg}$, but lower activity at 0.05 or $0.1 \mathrm{mg} / \mathrm{kg}$ compared with inorganic Se. In another study, Mahan \& Parrett ${ }^{(33)}$ reported that finishing pigs that received selenite had greater serum GPx activity compared with those with Se-enriched yeast, when both sources of Se were supplemented at $0 \cdot 1 \mathrm{mg} / \mathrm{kg}$ in a Se-deficient basal diet. However, difference in serum GPx activity was minimal when Se was supplemented at 0.3 or $0.5 \mathrm{mg} / \mathrm{kg}$. In the present study, the plasma GPx activity was the highest in the SY group on day 0 PI, suggesting greater bioavailability of organic Se and foretelling robuster resilience to oxidative insults.
Soyabean protein-chelated Se was a novel source of organic Se that was synthesised by chelating SS with hydrolysed soyabean proteins. Previously, SC has only been tested in broiler chicken in physiological state ${ }^{(35)}$. In that study, birds were fed a Se-deficient diet (NC), Se-replete diet (PC) or the Se-deficient diet supplemented with SC, SY or SS (same products as used in the present study) ${ }^{(35)}$. In comparison with the NC group, all sources of Se significantly increased Se deposition in liver and breast meat and enhanced blood GPx activity to the extent that is comparable with the PC group, while SY displayed the most 
Table 5. Diquat injection altered (false discovery rate (FDR)-adjusted $P<0.15)$ twenty-three liver metabolites in post-weaning pigs

\begin{tabular}{lcrc}
\hline Metabolite & ${ }_{*} \log _{2} \mathrm{FC}_{(\mathrm{PC} / \mathrm{NC})}$ & \multicolumn{1}{c}{$P$} & $\mathrm{FDR}$ \\
\hline Inositol-4-monophosphate & 2.06 & 0.001 & 0.046 \\
$\beta$-Glycerolphosphate & 1.83 & 0.001 & 0.046 \\
Succinate semialdehyde & 1.38 & 0.001 & 0.046 \\
1-Monostearin & 1.12 & 0.002 & 0.047 \\
2-Monoolein & 1.00 & 0.001 & 0.046 \\
Linoleic acid & 0.99 & 0.017 & 0.149 \\
Levodopa & 0.93 & 0.002 & 0.046 \\
Cholesterol & 0.56 & 0.002 & 0.046 \\
5-Oxoproline & 0.32 & 0.011 & 0.117 \\
Galactose & -0.20 & 0.012 & 0.122 \\
Aminomalonate & -0.45 & 0.015 & 0.145 \\
Malic acid & -0.48 & 0.005 & 0.081 \\
Adenine & -0.56 & 0.009 & 0.109 \\
Ascorbic acid & -0.67 & 0.006 & 0.084 \\
Isohexoic acid & -0.80 & 0.002 & 0.046 \\
Cysteine & -1.64 & 0.011 & 0.117 \\
Dehydroascorbic acid & -1.99 & 0.016 & 0.149 \\
Gluconic acid & -2.21 & 0.009 & 0.109 \\
Glutamine di(trimethylsilyl) & -2.40 & 0.009 & 0.109 \\
$\quad$ derivative & & & \\
Galactonic acid & -2.44 & 0.005 & 0.081 \\
Mannonic acid & -2.56 & 0.005 & 0.081 \\
Galacturonic acid & -2.66 & $<0.001$ & 0.046 \\
\hline
\end{tabular}

${ }^{*} \log _{2}$ (fold change) of metabolite in comparison between positive control (diquat injection) and negative control (saline injection). Metabolites were sorted based on $\log _{2}$ (fold change) from the largest to smallest.

prominent effect among all sources of $\mathrm{Se}^{(35)}$. Interestingly, the SY group had the lowest feed intake and weight gain during the $35-\mathrm{d}$ feeding trial. Findings from our study were not in agreement with regard to the effect of SY on growth performance. However, in consideration of the obvious difference in animal species and experimental design, direct comparison of results between the two studies is forbidden.

\section{Effects of selenium supplements on resilience to diquat-} induced oxidative stress

A trend of higher plasma lipid peroxidation adduct (MDA) that was observed only at 6 and $48 \mathrm{~h}$ PI (PC $v$. NC) suggests an acute oxidative stress in liver. Our finding is in agreement with Mao et $a l^{(22)}$ wherein the same dose of diquat as used in our study induced reversible oxidative stress in weanling pigs. The drastic surge of plasma cortisol at $6 \mathrm{~h}$ PI (PC $v$. NC) suggested induction of acute stress. Similarly, Wang et al. ${ }^{(7)}$ also reported radical increase of stress hormones (cortisol and adrenaline) that peaked at $1.5 \mathrm{~h}$ and remained elevated at $15 \mathrm{~h}$ post-diquat injection (10 mg/kg BW) in weanling pigs. In the present study, changes in number of circulating neutrophils post-diquat injection paralleled with the changes in plasma cortisol in comparison between the PC and NC groups. Whether or not diquat has direct effect on immune cell trafficking is unknown, but there is a rich literature identifying adrenal steroid hormones as the primary mediators that modulate leucocyte profiles and distribution under stress conditions ${ }^{(36)}$. Through either acute stress models or direct administration, circulating corticosterone was accompanied by a rapid increase in numbers of blood neutrophils and by a decrease in numbers of circulating lymphocytes in rats $^{(37,38)}$, whereas changes in leucocyte trafficking rapidly reversed after the cession of stress ${ }^{(37)}$. Therefore, changes in blood neutrophils after diquat exposure are probably mediated by stress hormones (i.e. cortisol). Dietary Se supplementation, regardless of the source of Se, attenuated the surge of cortisol and circulating neutrophils, suggesting the beneficial effect of Se on mitigating diquat-induced acute stress.

Endogenous antioxidant enzymes serve as critical defence against free radicals. GPx is responsible for removing lipid hydroperoxides. However, exaggerated production of hydrogen peroxide has been shown to inhibit cellular GPx activity ${ }^{(39)}$. In the present study, the lower plasma GPx activity (PC $v$. NC) at 6 and $48 \mathrm{~h}$ PI underscored compromised antioxidant defence and explained high plasma MDA content in the PC group. Zheng et $a l .{ }^{(40)}$ also observed reduction of plasma GPx activity $7 \mathrm{~d}$ post-diquat injection in post-weaning pigs. Liver and kidney are the main target organs of diquat toxicity ${ }^{(18,19,41)}$. In contrast to acute systemic stress, hepatic GPx and SOD activities are still depressed (PC $v$. NC) on day 7 PI, suggesting a lasting effect of diquat that depleted endogenous antioxidant enzymes in liver. Our finding is consistent with another study wherein oxidative insults remained evident in liver of post-weaning pigs on day 13 post-diquat injection $(10 \mathrm{mg} / \mathrm{kg} \mathrm{BW})^{(7)}$.

Sufficient Se supply is required to replenish cellular GPx activity in confrontation of oxidative stress. Rats fed a Se-deficient diet displayed increased vulnerability to diquat toxicity with devastating liver and kidney necrosis as compared with those fed a diet with normal Se content ${ }^{(42)}$. In the present study, the plasma GPx activity was the highest in the SY group post-diquat challenge. This might be partially explained by the pre-existing higher plasma GPx activity in SY before diquat challenge. Moreover, SY, but not SS or SC, restored plasma GPx activity to the level of the NC group at $6 \mathrm{~h}$, on day 2 and day 7 PI and reinstated hepatic GPx activity on day 7 PI. A large percentage $(>60 \%)$ of Se in SY existed as organic form (selenomethionine $)^{(10)}$. Studies have consistently found that organic Se associated with greater increase of plasma Se compared with inorganic Se, when both were supplemented at the same level in diets for growing or finishing pigs ${ }^{(11,12,16,33)}$. Plasma Se is readily mobilised for synthesis of GPx under acute oxidative insult, which possibly explained the greater GPx activity in SY pigs post-diquat injection.

Mao et al. ${ }^{(22)}$ observed reduction in plasma SOD activity in weaned pigs at day 7 post-diquat injection as the only time point measured in their study. However, the plasma SOD activity was not compromised by diquat injection in our study. The finding of enhanced SOD activity by different sources of Se since $24 \mathrm{~h}$ PI was intriguingly, as Se is not a known factor to regulate SOD activity. Inconsistent changes of plasma SOD activity in response to diquat and Se supplementation are enigmatic and need to be further explored.

\section{Dietary supplementation of selenised yeast diminished diquat-induced metabolic perturbation in liver}

Acute diquat poisoning is extremely detrimental to the function of liver and kidney ${ }^{(41)}$. Overwhelming hepatic oxidative stress and clear signs of hepatopathology were detected in mice after 


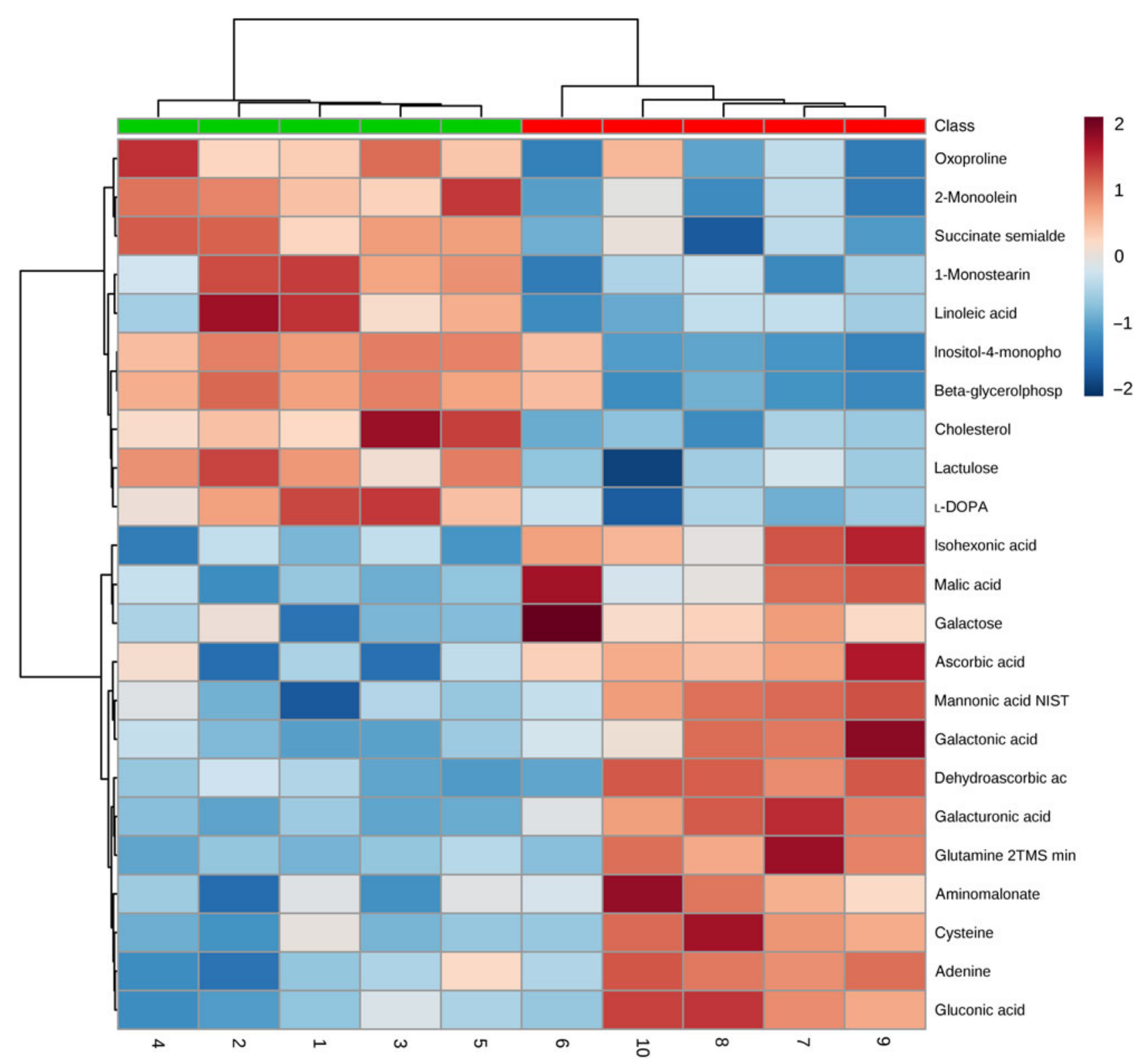

Fig. 2. Heat map and hierarchical clustering of twenty-three hepatic metabolites significantly affected at day 7 post-diquat challenge in nursery pigs. Class: $\mathbf{n}$, negative control without diquat challenge or dietary selenium supplementation; $\square$, positive control with diquat challenge without dietary selenium supplementation.

diquat exposure (intraperitoneal (i.p.) injection) at a dose of $125 \mathrm{mg} / \mathrm{kg}^{(43)}$. Nevertheless, in the present study, diquat exposure (i.p. injection at $10 \mathrm{mg} / \mathrm{kg}$ ) at a much lower dose increased MDA concentration in liver by approximately $20 \%$ (PC $v$. NC), suggesting induction of hepatic lipid peroxidation. Mao et al. $^{(22)}$ also observed elevated hepatic lipid peroxidation in pigs injected with the same dose of diquat as used in our study. Endogenous antioxidant enzymes act as buffer to neutralise reactive oxygen species and protect cellular lipids and proteins from oxidative damage. Reduction in activities of SOD and GPX in the liver (PC $v$. NC) highlighted that both enzymes were consumed to counteract diquat-induced redox disturbance, whereas organic Se supplements, namely SC and SY, replenished hepatic SOD and GPx, respectively.
Our study is the first to report global changes of hepatic metabolites (PC $v$. NC) in pigs in response to diquat injection (Fig. 2). As shown in the score plot of PCA analysis (Fig. 3), minimal overlapping area between samples from different treatments implies major difference in metabolic profiles between PC and NC. Relatively wide distribution of PC samples highlighted large within-group variation which is probably ascribed to individual variations in resilience to oxidative insult. Four metabolites (cysteine, oxoproline, ascorbic acid and dehydroascorbic acid) that are involved in the synthesis of cellular antioxidants (i.e. glutathione (GSH) and ascorbic acid) were altered in response to diquat challenge. Glutathione, a tripeptide that is present in relatively high concentration in mammalian cells $(0.5-10 \mathrm{mmol} / \mathrm{l})$, is readily oxidised to glutathione disulphide by free radicals and thus 


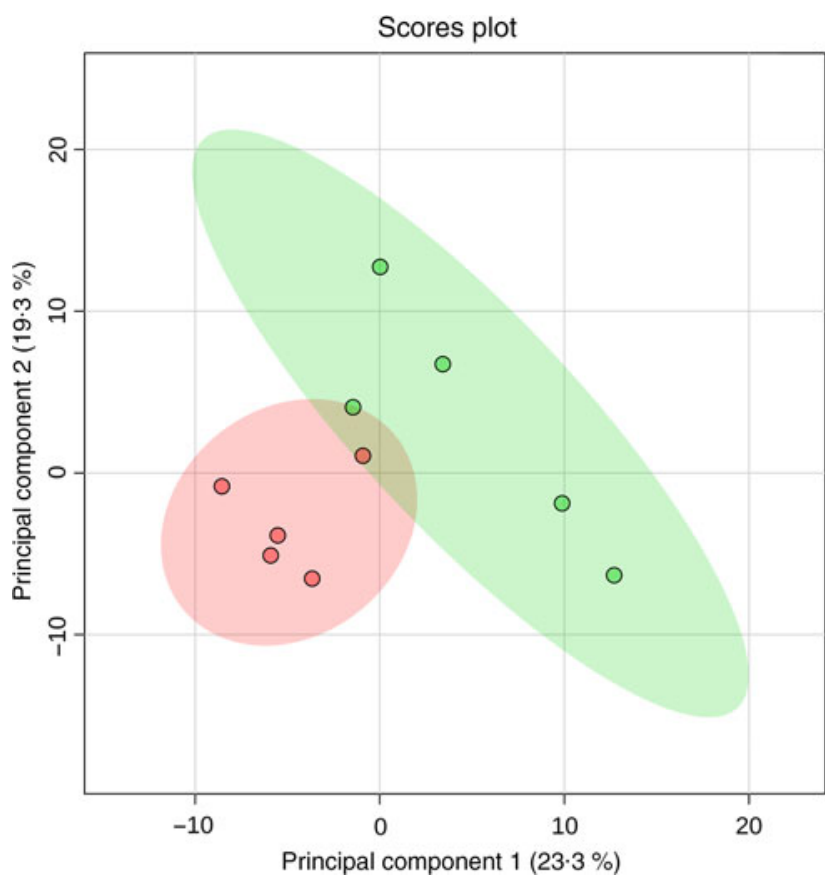

Fig. 3. Two-dimensional score plots of principal component analysis of hepatic metabolites in post-weaning piglets on day 7 post-diquat challenge. Confidence ranges of $95 \%$ are depicted as circled areas. Numbers listed in parentheses of each principal component indicate the variance explained. Dots indicate individual samples from the NC or PC group $(n 5)$, respectively. Negative control without diquat challenge or dietary selenium supplementation; $\bullet$, positive control with diquat challenge without dietary selenium supplementation.

protects cells against oxidative stress ${ }^{(44)}$. Among three constituent amino acids of GSH, the intracellular pool of cysteine in rat liver was relatively small $(0 \cdot 15-0 \cdot 25 \mathrm{mmol} / \mathrm{l})$ compared with that of glutamate $(2-4 \mathrm{mmol} / \mathrm{l})$ and glycine $(1.5-2 \mathrm{mmol} / \mathrm{l})^{(45)}$. Cysteine availability is one of the limiting factors in GSH synthesis in humans and rats ${ }^{(45-47)}$. In the present study, reduction of cysteine (PC $v$. NC; Table 5) in the liver presumably foretells the depletion of intracellular GSH. 5-Oxoproline is an intermediate metabolite of $\gamma$-glutamyl cycling in GSH synthesis. Consumption of a diet that is devoid of cysteine and methionine significantly increased plasma flux, oxidation and urinary excretion of oxoproline in humans ${ }^{(48)}$, suggesting that cysteine deficiency decreased salvage of oxoproline and probably compromised GSH synthesis. In the present study, the increase of 5-oxoproline in the liver by diquat challenge is consistent with the reduction of cysteine, which collectively suggested the depletion of GSH. Ascorbic acid (AA) acts as a major free radical scavenger in vivo and is converted to dehydroascorbic acid (DHA) upon oxidation. Plasma concentrations of AA and DHA serve as reliable biomarkers of oxidative stress caused by smoking ${ }^{(49)}$. Because of its large ascorbate store, the liver is considered a reservoir that maintains the homoeostasis of plasma ascorbate ${ }^{(50)}$. In the present study, a lower hepatic AA content in PC compared with NC underscored consumption of the AA store in response to diquat-induced oxidative insult. Under physiological conditions, intracellular DHA is instantly reduced to regenerate $\mathrm{AA}$ at the expense of cellular reductants (i.e. $\mathrm{NADH}, \mathrm{NADPH}$ or GSH) ${ }^{(51)}$. The reaction is primarily catalysed by NADPH-dependent thioredoxin reductase and, to a lesser extent, by glutathione-dependent DHA reductase ${ }^{(51,52)}$. As a selenoprotein, thioredoxin reductase activity in the liver is depressed in rats fed a Se-deficient diet ${ }^{(52)}$. However, in the presence of $\mathrm{H}_{2} \mathrm{O}_{2}$, DHA is readily hydrolysed and undergoes irreversible degradation in vitro, resulting in a loss of ascorbic acid ${ }^{(53)}$. Therefore, reduction in both AA and DHA (PC $v$. NC) presumably resulted from the depletion of cellular reductants and conditional Se deficiency under acute oxidative insult.

The finding of a unanimous increase of lipid metabolites ( $\beta$-glycerolphosphate, 1-monostearin, 2-monoolein, linoleic acid and cholesterol) (PC $v$. NC) highlighted an overall effect of diquat on hepatic lipid metabolism. Cell membrane lipids are extremely vulnerable to oxidative damage, while diquat exposure has shown to cause lipid peroxidation and liver necrosis ${ }^{(54)}$. It is plausible that increased lipid metabolites were derived from decomposition of cellular membranes. In addition, oxidative stress hypothetically impairs mitochondrial ATP production and subsequently triggers $\beta$-oxidation of cellular lipids, which might contribute to changes of lipid metabolites as well. A recent study with transcriptome analysis revealed the significant changes in gene sets associated with energy reserve and cellular lipid metabolic processes in the liver of diquat-challenged pigs ${ }^{(55)}$. Therefore, changes in lipid metabolites as observed in our study could also be mediated through transcriptional modulation of related genes. Furthermore, Seo et al. ${ }^{(56)}$ reported that treatment with $\mathrm{H}_{2} \mathrm{O}_{2}$ significantly increased the expression of genes related to cholesterol synthesis in HepG2 cells (a human liver cancer cell line), explaining the increase of cholesterol content in the liver of diquat-challenged pigs in our study.

In contrast to the increase of lipid metabolites, the unanimous reduction of galactose and sugar derivatives (gluconic acid, galactonic acid and galacturonic acid) in PC may be partially attributed to lower feed intake, as lactose accounted for $6 \%$ of the diet. Unlike humans, pigs have functional L-gulonolactone oxidase in the liver ${ }^{(57)}$ and thus can utilise glucose, galactose and oxidised sugar acids (i.e. gluconic acid, galactonic acid and galacturonic acid) as substrates for de novo synthesis of ascorbic acid ${ }^{(58)}$. The lower hepatic ascorbic acid content (PC $v$. NC), therefore, may be due in part to substrate deficiency because of low feed intake under oxidative stress. This might further aggravate diquat-induced oxidative stress in liver.

In our previous discussion, supplementation of SY was more effective in mitigating diquat-induced oxidative stress. Thus, only liver samples of the SY group were submitted for metabolome analysis. In agreement with the results of other analyses (i.e. oxidative measurements in blood and liver), SY partially recuperated diquat-induced metabolic perturbation in the liver (online Supplementary Fig. S1). This is supported by the fact that the $95 \%$ confidence zone of SY was largely aligned and overlapped with that of NC rather than PC samples in the score plot of PCA analysis. However, a substantial withingroup variation was also detected among SY samples and hampers detection of statistical difference for any metabolites that were altered by diquat challenge. The inconsistency in hepatic metabolome of SY samples may partially ascribe to the relatively large individual variations in post-challenge feed intake (Fig. 1), which may affect Se intake and thus affect 
susceptibility to diquat toxicity (Fig. 3). Future study with a larger sample size is warranted.

In conclusion, the present experiment confirms that intraperitoneal injection of diquat could induce acute oxidative stress and systemic inflammation, which provides a valuable pig model to investigate the mechanistic importance of exogenous antioxidants, such as Se, in human and animal health. The results also highlighted that supplementation of $0.3 \mathrm{mg} / \mathrm{kg}$ Se as Se-enriched yeast could prime the systemic antioxidant capacity and subsequently enhance resilience to diquat-induced oxidative stress and inflammation in weaned pigs. Diquat challenge altered lipid and galactose metabolism and reduction in metabolites associated with cellular antioxidant synthesis. However, the effect of SY on hepatic metabolome was not congruent among all samples emphasising the necessity of a larger sample size in future study. Neither SS nor SC displayed consistent antioxidant effects that is comparable with $\mathrm{SY}$ in battle against diquat-induced oxidative stress in weaned pigs.

\section{Acknowledgements}

We thank our research interns for their contribution to the animal trial and laboratory analysis.

The study was financially supported by Pancosma SA and NIFA Multi-State Fund. The funding sponsors had no role in experimental design, analyses, data interpretation, writing the manuscript or decision to publish the results.

N. D., Y. L., D. M. B. and P. J. conceived and designed the study. N. D., X. X., K. K. and Z. W. performed the animal trial and laboratory analysis. N. D., Y. L. and P. J. analysed the data and wrote the manuscript. All authors revised the manuscript.

D. M. B. was an employee of Pancosma SA. A. B. is a current employee of Pancosma SA. The remaining authors declare that the research was conducted in the absence of any commercial or financial relationships that could be construed as a potential conflict of interest.

\section{Supplementary material}

For supplementary materials referred to in this article, please visit https://doi.org/10.1017/S0007114520000689

\section{References}

1. Buchet A, Belloc C, Leblanc-Maridor M, et al. (2017) Effects of age and weaning conditions on blood indicators of oxidative status in pigs. PLOS ONE 12, e0178487.

2. Luo Z, Zhu W, Guo Q, et al. (2016) Weaning induced hepatic oxidative stress, apoptosis, and aminotransferases through MAPK signaling pathways in piglets. Oxid Med Cell Longev 2016, 4768541 .

3. Gabler NK, Koltes D, Schaumberger S, et al. (2018) Diurnal heat stress reduces pig intestinal integrity and increases endotoxin translocation. Transl Anim Sci 2, 1-10.

4. Zhu LH, Zhao KL, Chen XL, et al. (2012) Impact of weaning and an antioxidant blend on intestinal barrier function and antioxidant status in pigs. J Anim Sci 90, 2581-2589.

5. Liu G, Yu L, Martínez Y, et al. (2017) Dietary Saccharomyces cerevisiae cell wall extract supplementation alleviates oxidative stress and modulates serum amino acids profiles in weaned piglets. Oxid Med Cell Longev 2017, 7.

6. Zheng P, Yu B, He J, et al. (2013) Protective effects of dietary arginine supplementation against oxidative stress in weaned piglets. Br J Nutr 109, 2253-2260.

7. Wang AN, Cai CJ, Zeng XF, et al. (2013) Dietary supplementation with Lactobacillus fermentum 15007 improves the antioxidative activity of weanling piglets challenged with diquat. J Appl Microbiol 114, 1582-1591.

8. Rayman MP (2012) Selenium and human health. Lancet 379, 1256-1268.

9. Hanschmann EM, Godoy JR, Berndt C, et al. (2013) Thioredoxins, glutaredoxins, and peroxiredoxins - molecular mechanisms and health significance: from cofactors to antioxidants to redox signaling. Antioxid Redox Signal 19, 1539-1605.

10. Fairweather-Tait SJ, Collings R \& Hurst R (2010) Selenium bioavailability: current knowledge and future research requirements. Am J Clin Nutr 91, 1484s-1491s.

11. Mahan DC \& Peters JC (2004) Long-term effects of dietary organic and inorganic selenium sources and levels on reproducing sows and their progeny. J Anim Sci 82, 1343-1358.

12. Mahan DC, Cline TR \& Richert B (1999) Effects of dietary levels of selenium-enriched yeast and sodium selenite as selenium sources fed to growing-finishing pigs on performance, tissue selenium, serum glutathione peroxidase activity, carcass characteristics, and loin quality. J Anim Sci 77, 2172-2179.

13. Cao J, Guo F, Zhang L, et al. (2014) Effects of dietary selenomethionine supplementation on growth performance, antioxidant status, plasma selenium concentration, and immune function in weaning pigs. J Anim Sci Biotechnol 5, 46.

14. Gan F, Chen X, Liao SF, et al. (2014) Selenium-enriched probiotics improve antioxidant status, immune function, and selenoprotein gene expression of piglets raised under high ambient temperature. J Agric Food Chem 62, 4502-4508.

15. Jlali M, Briens M, Rouffineau F, et al. (2014) Evaluation of the efficacy of 2-hydroxy-4-methylselenobutanoic acid on growth performance and tissue selenium retention in growing pigs. $J$ Anim Sci 92, 182-188.

16. Kim YY \& Mahan DC (2001) Comparative effects of high dietary levels of organic and inorganic selenium on selenium toxicity of growing-finishing pigs. J Anim Sci 79, 942-948.

17. Osburn WO, Wakabayashi N, Misra V, et al. (2006) Nrf2 regulates an adaptive response protecting against oxidative damage following diquat-mediated formation of superoxide anion. Arch Biochem Biophys 454, 7-15.

18. Smith CV (1987) Effect of BCNU pretreatment on diquatinduced oxidant stress and hepatotoxicity. Biochem Biophys Res Commun 144, 415-421.

19. Spalding DJ, Mitchell JR, Jaeschke H, et al. (1989) Diquat hepatotoxicity in the Fischer-344 rat: the role of covalent binding to tissue proteins and lipids. Toxicol Appl Pharmacol 101, 319-327.

20. Alonso-Alvarez C \& Galvan I (2011) Free radical exposure creates paler carotenoid-based ornaments: a possible interaction in the expression of black and red traits. PLOS ONE 6, e19403.

21. Higuchi M, Oshida J, Orino K, et al. (2011) Wheat bran protects Fischer-344 rats from diquat-induced oxidative stress by activating antioxidant system: selenium as an antioxidant. Biosci Biotechnol Biochem 75, 496-499.

22. Mao X, Lv M, Yu B, et al. (2014) The effect of dietary tryptophan levels on oxidative stress of liver induced by diquat in weaned piglets. J Anim Sci Biotechnol 5, 49.

23. Wu J, Fiehn O \& Armstrong AW (2014) Metabolomic analysis using porcine skin: a pilot study of analytical techniques. Dermatol Online J 20, 13030/qt1ns2b5m5. 
24. Miyamoto S, Taylor SL, Barupal DK, et al. (2015) Systemic metabolomic changes in blood samples of lung cancer patients identified by gas chromatography time-of-flight mass spectrometry. Metabolites 5, 192-210.

25. Kind T, Wohlgemuth G, Lee DY, et al. (2009) FiehnLib: mass spectral and retention index libraries for metabolomics based on quadrupole and time-of-flight gas chromatography/mass spectrometry. Anal Chem 81, 10038-10048.

26. Ewan RC (1976) Effect of selenium on rat growth, growth hormone and diet utilization. J Nutr 106, 702-709.

27. Glienke LR \& Ewan RC (1977) Selenium deficiency in the young pig. J Anim Sci 45, 1334-1340.

28. Moreno-Reyes R, Egrise D, Nève J, et al. (2001) Selenium deficiency-induced growth retardation is associated with an impaired bone metabolism and osteopenia. J Bone Miner Res 16, 1556-1563.

29. Arthur JR, Nicol F \& Beckett GJ (1993) Selenium deficiency, thyroid hormone metabolism, and thyroid hormone deiodinases. Am J Clin Nutr 57, 236S-239S.

30. Henry PR \& Ammerman CB (1995) Selenium bioavailability. In Bioavailability of Nutrients for Animals: Amino Acids, Minerals, Vitamins, pp. 303-330 [CB Ammerman, DP Baker and AJ Lewis, editors]. London: Academic Press Limited.

31. Schrauzer GN (2000) Selenomethionine: a review of its nutritional significance, metabolism and toxicity. J Nutr 130, $1653-1656$.

32. Thomson CD, Burton CE \& Robinson MF (1978) On supplementing the selenium intake of New Zealanders. 1. Short experiments with large doses of selenite or selenomethionine. Br J Nutr 39, 579-587.

33. Mahan DC \& Parrett NA (1996) Evaluating the efficacy of selenium-enriched yeast and sodium selenite on tissue selenium retention and serum glutathione peroxidase activity in grower and finisher swine. J Anim Sci 74, 2967-2974.

34. Wang Y, Zhan X, Zhang X, et al. (2011) Comparison of different forms of dietary selenium supplementation on growth performance, meat quality, selenium deposition, and antioxidant property in broilers. Biol Trace Elem Res 143, 261-273.

35. Woods S, Whiting I, Rose S, et al. (2018) The effect of feeding different selenium sources on the antioxidant status of broiler chickens. Br Poult Abstr 14, 34-35.

36. Dhabhar FS (2006) Stress-induced changes in immune cell distribution and trafficking: implications for immunoprotection versus immunopathology. In Neural and Neuroendocrine Mechanisms in Host Defense and Autoimmunity, pp. 7-25 [CJ Welsh, MW Meagher and EM Sternberg, editors]. Boston, MA: Springer US.

37. Dhabhar FS, Miller AH, McEwen BS, et al. (1995) Effects of stress on immune cell distribution. Dynamics and hormonal mechanisms. J Immunol 154, 5511-5527.

38. Dhabhar FS, Miller AH, Stein M, et al. (1994) Diurnal and acute stress-induced changes in distribution of peripheral blood leukocyte subpopulations. Brain Behav Immun 8, 66-79.

39. Pigeolet E, Corbisier P, Houbion A, et al. (1990) Glutathione peroxidase, superoxide dismutase, and catalase inactivation by peroxides and oxygen derived free radicals. Mech Ageing Dev 51, 283-297.
40. Zheng P, Yu B, Lv M, et al. (2010) Effects of oxidative stress induced by diquat on arginine metabolism of postweaning pigs. Asian-Australas J Anim Sci 23, 98-105.

41. Jones GM \& Vale JA (2000) Mechanisms of toxicity, clinical features, and management of diquat poisoning: a review. $J$ Toxicol Clin Toxicol 38, 123-128.

42. Burk RF, Lawrence RA \& Lane JM (1980) Liver necrosis and lipid peroxidation in the rat as the result of paraquat and diquat administration. Effect of selenium deficiency. JClin Invest 65, 1024-1031.

43. Wu KC, Zhang Y \& Klaassen CD (2012) Nrf2 protects against diquat-induced liver and lung injury. Free Radic Res $\mathbf{4 6}$, $1220-1229$

44. Wu G, Fang YZ, Yang S, et al. (2004) Glutathione metabolism and its implications for health. J Nutr 134, 489-492.

45. Griffith OW (1999) Biologic and pharmacologic regulation of mammalian glutathione synthesis. Free Radic Biol Med 27, 922-935.

46. Grimble RF, Jackson AA, Persaud C, et al. (1992) Cysteine and glycine supplementation modulate the metabolic response to tumor necrosis factor alpha in rats fed a low protein diet. J Nutr 122, 2066-2073.

47. Lyons J, Rauh-Pfeiffer A, Yu YM, et al. (2000) Blood glutathione synthesis rates in healthy adults receiving a sulfur amino acid-free diet. Proc Natl Acad Sci U S A 97, 5071-5076.

48. Metges CC, Yu YM, Cai W, et al. (2000) Oxoproline kinetics and oxoproline urinary excretion during glycine- or sulfur amino acid-free diets in humans. Am J Physiol Endocrinol Metabol 278, E868-E876.

49. Lykkesfeldt J, Loft S, Nielsen JB, et al. (1997) Ascorbic acid and dehydroascorbic acid as biomarkers of oxidative stress caused by smoking. Am J Clin Nutr 65, 959-963.

50. Upston JM, Karjalainen A, Bygrave FL, et al. (1999) Efflux of hepatic ascorbate: a potential contributor to the maintenance of plasma vitamin C. Biochem J 342, 49-56.

51. Deutsch JC (2000) Dehydroascorbic acid. J Chromatogr A 881, 299-307.

52. May JM, Mendiratta S, Hill KE, et al. (1997) Reduction of dehydroascorbate to ascorbate by the selenoenzyme thioredoxin reductase. J Biol Chem 272, 22607-22610.

53. Deutsch JC (1998) Ascorbic acid oxidation by hydrogen peroxide. Anal Biochem 255, 1-7.

54. Burk RF, Hill KE, Awad JA, et al. (1995) Pathogenesis of diquatinduced liver necrosis in selenium-deficient rats: assessment of the roles of lipid peroxidation and selenoprotein P. Hepatology 21, 561-569.

55. Wang J, Li Z-X, Yang D-D, et al. (2019) Diquat determines a deregulation of IncRNA and mRNA expression in the liver of postweaned piglets. Oxid Med Cell Longev. 2019, 9.

56. Seo E, Kang H, Choi H, et al. (2019) Reactive oxygen speciesinduced changes in glucose and lipid metabolism contribute to the accumulation of cholesterol in the liver during aging. Aging Cell 18, e12895.

57. Drouin G, Godin J-R \& Pagé B (2011) The genetics of vitamin C loss in vertebrates. Curr Genomics 12, 371-378.

58. Isherwood FA, Chen YT \& Mapson LW (1954) Synthesis of $\mathrm{L}$-ascorbic acid in plants and animals. Biochem J 56, 1-15. 